\title{
CONTROLE QUÍMICO DE PLANTAS DANINHAS NA CULTURA DO GIRASSOL EM SOLO DE TEXTURA ARGILOSA
}

\author{
Alexandre M. Brighenti' ${ }^{1}$, Dionisio L. P. Gazziero ${ }^{1}$, Marcelo F. Oliveira ${ }^{1}$, \\ Elemar Voll ${ }^{1}$ e José E. Pereira ${ }^{1}$
}

'Embrapa Soja. Caixa Postal 231. Londrina, PR 86001-970

\section{RESUMO}

A falta de herbicidas registrados para o controle de plantas daninhas dicotiledôneas na cultura do girassol é um dos principais problemas que afeta a sua produtividade. Desse modo, um experimento foi conduzido em área da Embrapa Soja, em Londrina-PR, a fim de avaliar o controle de plantas daninhas dicotiledôneas e a eficiência agronômica de herbicidas aplicados em condições de pré-emergência, em solo de textura argilosa. Os tratamentos aplicados foram sulfentrazone (350 e $600 \mathrm{~g} / \mathrm{ha}$ ), acetochlor (2100 e $2520 \mathrm{~g} / \mathrm{ha}$ ) e oxyfluorfen (360 e $480 \mathrm{~g} / \mathrm{ha}$ ), além das testemunhas capinada e sem capina. O sulfentrazone aplicado na dose de $350 \mathrm{~g}$ /ha foi seletivo para o girassol cultivar M 734, sendo eficiente, principalmente, no controle do amendoim-bravo e da corda-de-viola. O acetochlor não foi eficiente no controle do amendoim-bravo. O oxyfluorfen (360 g/ha) foi seletivo para o girassol cultivar M 734, controlando o amendoim-bravo. Em solos de textura arenosa e com baixos teores de matéria orgânica, os efeitos fitotóxicos desses produtos sobre o girassol, provavelmente, serão maiores.

Palavras-chave: Helianthus annuus, Asteraceae, sulfentrazone, acetochlor, oxyfluorfen.

\section{ABSTRACT \\ Weed control in sunflower on clay textured soil}

Lack of broadleaf chemical control options in sunflower is a major production problem. An experiment was conducted at Embrapa Soja in Londrina, Paraná State, Brazil, to evaluate broadleaf weed control and agronomic efficiency of preemergence herbicides applied on clay soil. The treatments were: sulfentrazone ( $350 \mathrm{and} 600 \mathrm{~g} / \mathrm{ha})$, acetochlor $(2100$ and $2520 \mathrm{~g} / \mathrm{ha})$ and oxyfluorfen (360 and $480 \mathrm{~g} / \mathrm{ha}$ ), weed and hand hoeing treatments. Sulfentrazone applied at $350 \mathrm{~g} / \mathrm{ha}$ was seletive to sunflower cultivar M 734 and efficient in controlling wild poinsettia (Euphorbia heterophylla) and morningglory (Ipomoea grandifolia). Acetochlor was not efficient in wild poinsettia control. Oxyfluorfen applied at $360 \mathrm{~g} /$ ha was seletive to sunflower cultivar M 734 and efficient in wild poinsettia control. The risk of fitotoxicity appears to be greater on low organic matter and coarse textured soils.

Key words: Helianthus annuus, Asteraceae, sulfentrazone, acetochlor, oxyfluorfen.

\section{INTRODUÇÃO}

A presença de invasoras durante as primeiras etapas do ciclo de cultivo do girassol resulta em plantas cloróticas, de menor porte, com diminuição severa da área foliar, do diâmetro do caule e do tamanho do capítulo (Blamey et al., 1997). Quando são analisados os componentes de rendimen- to, o número de aquênios por capítulo é aquele que apresenta maior prejuízo (Bedmar et al., 1983). Um dos métodos que podem ser utilizados para a eliminação dessas espécies é o químico. Entretanto, a disponibilidade de herbicidas registrados para a cultura do girassol é muito limitada no Brasil. Apenas o trifluralin, o sethoxydim e o alachlor são registrados no Brasil para o controle de plantas daninhas em girassol, exigindo um 
rígido programa de controle cultural, mecânico e químico (Castro et al., 1996). Além disso, a pequena área cultivada com o girassol, quando comparada com outras como a soja, a canade-açúcar e o milho, não proporciona incentivo às empresas no sentido de desenvolver moléculas para o controle de invasoras em girassol. O problema se agrava ainda mais quando ocorre predominância de plantas daninhas de folhas largas, pois, dos três herbicidas mencionados, apenas o alachlor atua sobre algumas espécies dicotiledôneas, sendo os demais eficazes no controle de gramíneas (Rodrigues e Almeida, 1995).

O objetivo deste trabalho foi avaliar a seletividade e o controle de plantas daninhas dicotiledôneas, em função de herbicidas aplicados em condições de pré-emergência, na cultura do girassol, em solo de textura argilosa.

\section{MATERIAL E MÉTODOS}

O experimento foi instalado na Embrapa Soja, Londrina, PR. O solo foi classificado como Latossolo Roxo distrófico com 77,15\% de argila, $15,35 \%$ de silte e 7,50\% de areia e $2,40 \%$ de matéria orgânica. O delineamento experimental utilizado foi blocos casualizados com quatro repetições. Cada bloco foi constituído pelos tratamentos sulfentrazone (350 e $600 \mathrm{~g} / \mathrm{ha})$, acetochlor $(2100$ e $2520 \mathrm{~g} /$ ha) e oxyfluorfen (360 e $480 \mathrm{~g} / \mathrm{ha}$ ), além das testemunhas capinada e sem capina. A área das parcelas foi de $6 \mathrm{~m}^{2}(3 \mathrm{~m}$ x $2 \mathrm{~m}$ ). A adubação de semeadura foi realizada utilizando $350 \mathrm{~kg} /$ ha de 5-25-25 com incorporação feita por grade niveladora. Aos 30 dias após a semeadura (DAS), foi realizada uma adubação em cobertura com $20 \mathrm{~kg}$ de nitrogênio/ ha e aplicado boro, via foliar, na dosagem de $1,2 \mathrm{~kg} / \mathrm{ha}$. A semeadura foi realizada em 15 de março de 1999, utilizando o híbrido M 734, num espaçamento de $0,7 \mathrm{~m}$ entre as linhas, com quatro sementes por metro linear. A aplicação dos herbicidas foi realizada no mesmo dia, em condição de pré-emergência. Foi utilizado um pulverizador costal, à pressão constante (mantida por $\mathrm{CO}_{2}$ comprimido) de $2,45 \mathrm{~kg} / \mathrm{cm}^{2}$, equipado com barra de $2 \mathrm{~m}$ de largura e quatro bicos de jato plano (leque) $11002 \mathrm{DG}$, distanciados de $0,5 \mathrm{~m}$, com volume de pulverização equivalente a 200 1/ha. Por ocasião da aplicação dos produtos, a temperatura do ambiente era de $30^{\circ} \mathrm{C}$, a umidade relativa do ar de $61 \%$, com solo úmido na superfície e velocidade do vento de $6 \mathrm{~km} / \mathrm{h}$. O efeito dos herbicidas no controle das espécies invasoras foi avaliado aos 30 DAS utilizando a escala visual de $0-100 \%$, onde $0 \%$ representava nenhum controle e $100 \%$ o controle total. Além disso, foi avaliada a biomassa seca de plantas daninhas na pré-colheita do girassol. O grau de fitotoxicidade foi avaliado através de escala percentual aos 20 e 30 DAS, onde $0 \%$ correspondeu à ausência de sintomas e $100 \%$ à morte total de plantas. Foram avaliados os diâmetros de caule e de capítulo, além da biomassa seca de plantas de girassol. O teor de óleo foi determinado através de ressonância magnética nucle- ar, com equipamento UMR, marca Oxford, modelo 400.

\section{RESULTADOS E DISCUSSÃO}

Os valores médios da biomassa seca de plantas daninhas não diferiram estatisticamente da testemunha sem capina em função da aplicação das doses de acetochlor e oxyfluorfen (Tabela 1). Entretanto, as doses de sulfentrazone proporcionaram controle eficiente das plantas daninhas, não diferindo da testemunha capinada. Com relação aos valores médios de percentagem de controle das espécies daninhas, o sulfentrazone proporcionou controle acima de $88 \%$ para amendoim-bravo e corda-de-viola nas duas doses aplicadas; a aplicação da menor dose resultou em controle mediano do picão-preto $(71 \%)$. O sulfentrazone, aplicado em condições de pré-emergência, causou efeitos fitotóxicos às plantas de girassol mas não afetou a produtividade da cultura (Thompson et al., 1999).

Foi obtido controle do picão-preto acima de $87 \%$, em função da aplicação das doses de acetochlor. Entretanto, esse herbicida não foi eficiente no controle do amendoim-bravo. Para o oxyfluorfen, ocorreu o inverso. Foram obtidas percentagens de controle do amendoim-bravo acima de $83 \%$, sendo esse produto ineficiente no controle de picão-preto.

Com relação à fitotoxicidade causada pelos herbicidas à cultura, tanto o sulfentrazone $(350 \mathrm{~g} / \mathrm{ha})$ quanto o oxyfluorfen $(360 \mathrm{~g} / \mathrm{ha})$ apresentaram valores baixos, não diferindo estatisticamente da testemunha aos 30 DAS (Tabela 2). Com relação ao diâmetro do caule, os valores obtidos não diferiram estatisticamente da testemunha capinada em função das doses dos herbicidas, à exceção do acetochlor (2100 $\mathrm{g} / \mathrm{ha}$ ). Os valores obtidos para o diâmetro de capítulo foram estatisticamente semelhantes à testemunha capinada, menos para o acetochlor. Para o teor de óleo, os valores obtidos não diferiram estatisticamente da testemunha capinada em função dos tratamentos. Com relação à biomassa seca de plantas de girassol, os valores obtidos em função das menores doses de sulfentrazone e oxyfluorfen não diferiram estatisticamente da testemunha capinada. Todos os herbicidas utilizados são produtos adsorvíveis pelos colóides do solo, tanto da argila como da matéria orgânica. Assim, em solos de textura média e arenosa e/ou com baixos teores de matéria orgânica, o efeito fitotóxico dessas doses, provavelmente, será maior.

\section{CONCLUSÃO}

O sulfentrazone aplicado na dose de $350 \mathrm{~g} / \mathrm{ha}$ foi seletivo para o girassol cultivar M 734, sendo eficiente, principalmente, no controle do amendoim-bravo e corda-de-viola. 
Tabela 1. Resultados médios da biomassa seca de plantas daninhas (BSPD) e percentagem de controle do Euphorbia heterophylla), Bidens pilosa e da Ipomoea grandifolia, em função das doses dos herbicidas. Embrapa Soja, Londrina-PR. 1999.

\begin{tabular}{|c|c|c|c|c|c|}
\hline \multirow{2}{*}{ Tratamento } & \multirow{2}{*}{$\begin{array}{l}\text { Dose } \\
\text { (g/ha) }\end{array}$} & \multirow{2}{*}{$\begin{array}{c}\text { BSPD } \\
\text { (g) }\end{array}$} & \multicolumn{3}{|c|}{ Controle (\%) } \\
\hline & & & Amendoim-bravo & Picão-preto & Corda-de-viola \\
\hline Testemunha capinada & 0 & $0,00 \mathrm{C}^{1}$ & $100,0 \mathrm{~A}^{1}$ & $100,0 \mathrm{~A}^{1}$ & $100,0 \mathrm{~A}^{1}$ \\
\hline Sulfentrazone & 350 & $7,85 \mathrm{BC}$ & $88,8 \mathrm{AB}$ & $71,2 \mathrm{~B}$ & $91,2 \mathrm{~A}$ \\
\hline Sulfentrazone & 600 & $2,68 \mathrm{C}$ & $98,2 \mathrm{~A}$ & $91,5 \mathrm{~A}$ & $100,0 \mathrm{~A}$ \\
\hline Acetochlor & 2100 & $32,05 \mathrm{~A}$ & $35,0 \mathrm{D}$ & $87,5 \mathrm{~A}$ & $37,5 \mathrm{~B}$ \\
\hline Acetochlor & 2520 & $26,81 \mathrm{~A}$ & $52,5 \mathrm{C}$ & $92,5 \mathrm{~A}$ & $88,8 \mathrm{~A}$ \\
\hline Oxyfluorfen & 360 & $21,49 \mathrm{AB}$ & $83,8 \mathrm{~B}$ & $30,0 \mathrm{C}$ & $42,5 \mathrm{~B}$ \\
\hline Oxyfluorfen & 480 & $21,40 \mathrm{AB}$ & $88,8 \mathrm{AB}$ & $37,5 \mathrm{C}$ & $50,0 \mathrm{~B}$ \\
\hline Testemunha sem capina & 0 & $29,16 \mathrm{~A}$ & $0,0 \mathrm{E}$ & $0,0 \mathrm{D}$ & $0,0 \mathrm{C}$ \\
\hline C.V. & & 36,5 & 9,0 & 9,0 & 14,8 \\
\hline
\end{tabular}

${ }^{1}$ Médias seguidas pelas mesmas letras na coluna não diferem entre si a 5\% de probabilidade pelo teste de Tukey.

Tabela 2. Resultados médios da percentagem de fitotoxicidade aos 20 e 30 dias após a semeadura (DAS), do diâmetro de caule e do capítulo, do teor de óleo e da biomassa seca de plantas de girassol (BSPG), em função das doses de herbicidas. Embrapa Soja, Londrina-PR, 1999.

\begin{tabular}{|c|c|c|c|c|c|c|c|}
\hline \multirow{3}{*}{ Tratamento } & \multirow{3}{*}{$\begin{array}{c}\text { Dose } \\
\text { (g/ha) }\end{array}$} & \multicolumn{2}{|c|}{ Fitotoxicidade (\%) } & \multirow{3}{*}{$\begin{array}{c}\text { Diâmetro do } \\
\text { caule }(\mathrm{mm})\end{array}$} & \multirow{3}{*}{$\begin{array}{l}\text { Diâmetro do } \\
\text { Capítulo }(\mathrm{cm})\end{array}$} & \multirow{3}{*}{$\begin{array}{c}\text { Teor de } \\
\text { Óleo }(\%)\end{array}$} & \multirow{3}{*}{$\begin{array}{c}\text { BSPG } \\
(\mathrm{g})\end{array}$} \\
\hline & & \multicolumn{2}{|c|}{ Dias Após a Semeadura } & & & & \\
\hline & & 20 & 30 & & & & \\
\hline Testemunha capinada & 0 & $0,0 \mathrm{E}$ & $0,0 \mathrm{C}$ & $23,40 \mathrm{~A}$ & $17,35 \mathrm{~A}$ & $43,1 \mathrm{~A}$ & $491,25 \mathrm{~A}$ \\
\hline Sulfentrazone & 350 & $15,0 \mathrm{DE}$ & $3,8 \mathrm{C}$ & $23,67 \mathrm{~A}$ & $16,40 \mathrm{AB}$ & $41,4 \mathrm{~A}$ & $391,25 \mathrm{AB}$ \\
\hline Sulfentrazone & 600 & $50,0 \mathrm{AB}$ & $30,0 \mathrm{AB}$ & $20,20 \mathrm{AB}$ & $15,80 \mathrm{ABC}$ & $39,6 \mathrm{~A}$ & $345,00 \mathrm{AB}$ \\
\hline Acetochlor & 2100 & $16,2 \mathrm{DE}$ & $21,2 \mathrm{~B}$ & $17,15 \mathrm{~B}$ & $12,60 \mathrm{D}$ & $41,9 \mathrm{~A}$ & $262,50 \mathrm{~B}$ \\
\hline Acetochlor & 2520 & $26,2 \mathrm{CD}$ & $25,0 \mathrm{AB}$ & $18,35 \mathrm{AB}$ & $13,85 \mathrm{BCD}$ & $39,9 \mathrm{~A}$ & $292,50 \mathrm{~B}$ \\
\hline Oxyfluorfen & 360 & $36,2 \mathrm{BC}$ & $16,2 \mathrm{BC}$ & $20,60 \mathrm{AB}$ & $15,80 \mathrm{ABC}$ & $41,6 \mathrm{~A}$ & $397,50 \mathrm{AB}$ \\
\hline Oxyfluorfen & 480 & $60,0 \mathrm{~A}$ & $38,8 \mathrm{~A}$ & $20,00 \mathrm{AB}$ & $14,50 \mathrm{ABCD}$ & $39,9 \mathrm{~A}$ & 296,25 B \\
\hline Testemunha sem capina & 0 & $00,0 \mathrm{E}$ & $00,0 \mathrm{C}$ & $16,85 \mathrm{~B}$ & $13,45 \mathrm{CD}$ & $41,1 \mathrm{~A}$ & $270,00 \mathrm{~B}$ \\
\hline C.V. & & 30,4 & 40,0 & 11,8 & 8,1 & 4,0 & 19,5 \\
\hline
\end{tabular}

${ }^{1}$ Médias seguidas pelas mesmas letras na coluna não diferem entre si a $5 \%$ de probabilidade pelo teste de Tukey.

O acetochlor não foi eficiente no controle do amendoim-bravo.

O oxyfluorfen na dose de $360 \mathrm{~g} /$ ha foi seletivo para o girassol cultivar M 734, controlando o amendoim-bravo.

\section{AGRADECIMENTOS}

Os autores agradecem aos colegas técnicos agrícolas da Embrapa Soja, Roberval A. Fagundes, Esmael da Silva, Mário Nakano e Reinaldo Teruhico Moriyama pela colaboração.

\section{LITERATURA CITADA}

BEDMAR, F.; LEADEN, M.; EYHERABIDE, J. Efectos de la competencia de las malezas con el girasol. IX Reunión Argentina sobre la Maleza y su Control. ASAM, vol.11, n. 4, p.51-61. 1983.

BLAMEY, F.P.C.; ZOLLINGER, R.K.; SCNEITER, A.A. Sunflower production and culture. In: SCNEITER, A.A. Sunflower science and technology. Madison, Wisconsin: The Amer. Soc. of Agronomy, 1997. p. 595-670.

CASTRO, C.; CASTIGLIONI, V.B.R.; BALLA, A.; LEITE, R.M.V.B.C.; KARAM, D.; MELLO, H.C.; 
GUEDES, L.C.A.; FARIAS, J.R.B. A cultura do girassol. Londrina: EMBRAPA-CNPSo, 1996.36 p. (EMBRAPACNPSo, Circular Técnica, 13).

RODRIGUES, B. N.; ALMEIDA, F. S. Guia de herbicidas. 3 ed. Londrina, PR, 1995. 675 p.
THOMPSON, C.; SCHLEGEL, A.; STAHLMAN, P. Sulfentrazone (Spartan or Authority), a potencial new herbicide in no-till sunflower. Proceeedings of $21^{\text {st }}$ Sunflower Research Workshop. Nacional Sunflower Association. Fargo-North Dakota, 1999. p.21-22. 